ATUALIZAÇÃO

\title{
ESTUDO DE PATÓGENOS \\ DE POTENCIAL ZOONÓTICO \\ EM PROCIONÍDEOS
}

Flávio de Rezende Guimarães, ${ }^{1}$ Thelma Michella Saddi, ${ }^{2}$ Julio Roquete Cardoso, ${ }^{3}$

Luciana Batalha de Miranda Araújo ${ }^{4}$ e Eugênio Gonçalves de Araújo ${ }^{4}$

\section{RESUMO}

Os procionídeos são animais de hábitos terrestres e arbóreos, encontrados em diferentes habitats. Embora classificados como carnívoros, englobam importantes espécies onívoras que, além de serem dispersoras de sementes de frutos, exercem influência sobre o tamanho das populações de suas presas vertebradas e servem como fonte de alimento para os grandes felinos silvestres. Apesar dos benefícios que os procionídeos conferem ao meio ambiente, seu contato com o ambiente urbano pode trazer riscos à saúde. Podem ser acometidos por patógenos adquiridos dos animais domésticos que vivem no entorno das Unidades de Conservação e transmiti-los ou servir de reservatório para outros animais e para o homem. Portanto, esta atualização objetivou realizar um levantamento dos estudos de prevalência, detecção e isolamento de patógenos com potencial zoonótico encontrados nas espécies de procionídeos mais amplamente distribuídas nas Américas.

DESCRITORES: Zoonose. Procionidae. Nasua. Procyon. Potos.

\section{ABSTRACT}

Study of the zoonotic potential of different pathogens in procyonids

Procyonids are animals with terrestrial and arboreal habits, found in different habitats. Although classified as carnivores, this family includes important species with omnivorous habits. Besides being fruit seed dispersers, they may influence the size of their vertebrate prey population and serve

1 Departamento de Ciências Básicas e Produção Animal, Faculdade de Agronomia, Medicina Veterinária e Zootecnia, Universidade Federal do Mato Grosso, Cuiabá, MT.

2 Programa de Pós-Graduação em Ciência Animal, Universidade Federal de Goiás (UFG), Goiânia, GO.

3 Departamento de Morfologia, Instituto de Ciências Biológicas, UFG.

4 Departamento de Medicina Veterinária, Escola de Veterinária e Zootecnia, UFG.

Endereço para correspondência: Flávio de Rezende Guimarães, Universidade Federal do Mato Grosso. Faculdade de Agronomia, Medicina Veterinária e Zootecnia, Departamento de Ciências Básicas e Produção Animal. Av. Fernando Corrêa da Costa, S/N. Coxipó. CEP 78075-000, Cuiabá, MT, Brasil. E-mail: flavio.r.guimaraes@bol.com.br

Recebido para publicação em: 8/6/2011. Revisto em: 18/11/2011. Aceito em: 13/2/2012. 
as food source for large wild cats. Despite the benefits that procyonids represent to the environment, their contact with the urban environment can bring health risks. Procyonids may be affected by pathogens acquired from domestic animals that live around the protected areas, and transmit or serve as reservoir of pathogens to other animals and to humans. Thus, this review aimed to search for articles on the prevalence, detection and isolation of pathogens with zoonotic potential found in the most widely distributed procyonids species in the Americas.

KEY WORDS: Zoonosis. Procyonids. Nasua. Procyon. Potos.

\section{INTRODUÇÃO}

Representando uma das 11 famílias tradicionais de mamíferos da ordem Carnívora, os procionídeos compreendem seis gêneros com 14 espécies, geograficamente distribuídas nas Américas. Englobam desde espécies arbóreas tropicais essencialmente frugívoras, como são o jupará (Potos spp.) e o olingo (Bassaricyon spp.), até espécies onívoras de hábitos terrestres e arbóreos encontradas em diferentes habitats, como os quatis (Nasua spp.) e os guaxinins (Procyon spp.) (Koepfli et al., 2007).

Apesar dos benefícios que os procionídeos representam para o meio ambiente, a aproximação desses ou de outras espécies silvestres com os seres humanos e seus animais domésticos pode trazer problemas. Tal proximidade pode transferir patógenos de animais silvestres para populações humanas e de animais domésticos (Rodrigues et al., 2006; Aguirre, 2009) ou vice-versa (Dantas-Torres et al., 2010), o que pode resultar em redução significativa do número de indivíduos das espécies acometidas (Aguirre, 2009). Tal diminuição poderia ainda gerar reflexos no equilíbrio entre as populações de animais silvestres, por interferência na cadeia alimentar, ou, segundo Alves-Costa e Eterovick (2007), trazer consequências para a própria dinâmica florestal caso envolva espécies frugívoras.

Neste sentido, os estudos de Pereira et al. (2001), Milanelo et al. (2009) e Voltarelli et al. (2009) mostram que os parques estaduais que possuem animais silvestres podem tornar-se um problema de saúde pública para os visitantes ou para a população de seu entorno se os animais silvestres ali presentes forem portadores de patógenos com potencial zoonótico. Pimentel et al. (2009) sugerem que este raciocínio se aplica também aos zoológicos que albergam animais nas mesmas condições.

Adicionalmente, as espécies de mosquitos ou flebótomos urbanos ou silvestres, sabidamente hospedeiros intermediários de vários agentes etiológicos, podem albergar e transmitir patógenos adquiridos dos animais do ambiente silvestre ou urbano.

Assim, a presente revisão de literatura tem como objetivo abordar estudos de prevalência de patógenos com potencial zoonótico encontrados nas espécies de procionídeos mais amplamente distribuídas nas Américas: o quati (Nasua nasua), o guaxinim (Procyon lotor), o jupará (Potos flavus) e o mão-pelada (Procyon cancrivorus). 


\section{ATUALIZAÇÃO DE LITERATURA}

Procionídeos

Os procionídeos pertencem à Classe Mammalia, Ordem Carnívora e Subordem Caniformia. Incluem os gêneros: Bassaricyon (com cinco espécies), Bassariscus (duas espécies), Nasua (duas espécies), Nasuella (uma espécie), Potos (uma espécie) e Procyon (três espécies) (Wilson \& Reeder, 2005), todos habitando naturalmente as Américas (Evans, 2001).

São animais de pequeno a médio porte, com cauda longa a moderadamente longa, na qual se encontram vários anéis escuros (Evans, 2001). Possuem pelagem densa e membros curtos, com cinco dedos cada, os quais possuem garras (Teixeira \& Ambrosio, 2007). A dentição é adequada a uma dieta onívora (Evans, 2001), de maneira que seus dentes molares são grandes e bem adaptados para esmagar os alimentos (Kollias \& Abou-Madi, 2007).

Procionídeos são geralmente noturnos ou crepusculares, exceto os quatis (Kollias \& Abou-Madi, 2007). São extremamente ágeis, têm facilidade para subir em árvores altas e possuem mãos bem adestradas para segurar e manipular objetos (Evans, 2001), o que lhes permite serem bons cavadores e escaladores (Teixeira \& Ambrosio, 2007). Podem usar parcial ou totalmente a sola dos pés para se apoiar no solo (Kollias \& Abou-Madi, 2007).

Patógenos zoonóticos

A presença de doenças em populações silvestres, mesmo sem a ocorrência de surtos epidêmicos, pode acarretar modificações nos ecossistemas ou biomas e, consequentemente, afetar os seus padrões de sustentabilidade (Vieira, 2009).

Determinados patógenos associados aos procionídeos podem extrapolar o universo silvestre e acometer espécies de animais domésticos e o próprio homem. Enfermidades que envolvem os procionídeos e o homem, como raiva, arboviroses, tripanossomose, leishmaniose, leptospirose e algumas doenças fúngicas serão abordadas a seguir.

Raiva

A raiva é uma antropozoonose conhecida e temida desde os tempos mais remotos, caracterizada por uma encefalomielite aguda fatal nos animais domésticos e selvagens e também no ser humano (Kaplan et al., 1986; Acha \& Szyfres, 2003). É mantida e perpetuada na natureza por diferentes espécies animais, como os carnívoros domésticos e silvestres, denominados reservatórios, incluindo também os morcegos (Kaplan et al., 1986; Smith et al., 1996).

Os limites geográficos da raiva enzoótica nas espécies consideradas reservatórios são dinamicamente temporais. As áreas que contêm o vírus podem 
se expandir em razão do aumento das populações, da migração ou transmissão do vírus por meio das interações entre as populações de animais. Desde a década de 1950, por exemplo, os guaxinins têm sido reconhecidos como importante reservatório no sudeste dos Estados Unidos. Uma variante do vírus que os acomete é considerada enzoótica em todos os estados da costa leste dos Estados Unidos, assim como no Alabama, Ohio, Pensilvânia, Tennessee, Vermont e Virginia Ocidental (Blanton et al., 2008).

A variante genotípica que acomete os guaxinins nos Estados Unidos se distribui para a fronteira com o Canadá. Representa uma consequência evolucionária da preferência viral pelo hospedeiro: guaxinins transmitiram para outros guaxinins e, depois de certo número de passagens, o vírus tornou-se um genótipo específico que, apesar de poder acometer outras espécies animais, é transmitido mais eficientemente dentro das suas próprias populações hospedeiras (Murphy et al., 1999).

Nos Estados Unidos e Canadá, a raiva continua sendo um grande problema de saúde pública, embora estes países sejam desenvolvidos. Programas efetivos de vacinação de animais de estimação têm controlado a doença em cães domésticos em ambos os países, mas ela persiste na forma silvestre (Sterner et al., 2009). A mesma situação ocorreu na Europa onde, nas últimas décadas, com o eficiente controle da doença nos animais domésticos, os animais silvestres passaram a ser considerados os principais transmissores da raiva (Jorge et al., 2010a).

Em Ontário, Canadá, entre 1999 e 2006 a variante do vírus da raiva que acomete guaxinins causou 132 óbitos em animais, sendo 98,5\% (130/132) destes os próprios guaxinins. O quadro clínico era caracterizado por ataxia, vocalizações e agressões, até mesmo contra cães (Rosatte et al., 2007). Ainda no Canadá, foram registrados 229 casos de raiva animal em animais silvestres e domésticos no ano de 2006, cinco dos animais acometidos eram guaxinins. Em 2007, o total de casos aumentou para 273, dos quais $89 \%$ (243) ocorreram em animais silvestres. Dentre estes, foram acometidos 59 guaxinins, os quais corresponderam a $24,28 \%$ do total de casos em animais silvestres (Blanton et al., 2008).

Um estudo realizado nos Estados Unidos mostrou que, naquele país, a raiva também ocorre principalmente em animais silvestres. No ano de 2006, de 7.259 casos diagnosticados em animais, $92,1 \%$ (6393) eram silvestres e os guaxinins (2.615) corresponderam a 40,9\% do total de óbitos. No ano de 2007, a proporção de animais silvestres acometidos pela raiva aumentou para 93,4\% (6.776) do total de óbitos em animais, novamente infectando guaxinins (2.659), que corresponderam a 39,2\% do total. A transmissão do vírus enzoótico dentro de uma espécie, uma vez estabelecida, pode persistir regionalmente por décadas (Blanton et al., 2008).

Aréchiga-Ceballos et al. (2010) relataram que, em fevereiro de 2008, três quatis da espécie Nasua narica foram achados mortos em um parque de lazer em Cancun, no México. Títulos antirrábicos $(1,3 \mathrm{UI} / \mathrm{mL})$ foram encontrados em um dos seis quatis que conviviam com os animais mortos. Os autores sugerem a condução 
de estudos sobre vigilância e patogenia da raiva em quatis e morcegos insetívoros da região, visando esclarecer o papel dessas espécies como potenciais reservatórios emergentes ou ainda não identificados do vírus.

No Brasil, segundo o Ministério da Agricultura, Pecuária e Abastecimento (MAPA), a principal espécie animal transmissora da raiva ao ser humano continua sendo o cão. No entanto, a participação dos morcegos na propagação do vírus é cada vez maior, podendo ser esses os principais responsáveis pela manutenção do vírus no ambiente silvestre. Identificações positivas do vírus da raiva já foram descritas em animais silvestres da fauna brasileira, inclusive em mãos-peladas (Procyon cancrivorous) (Brasil, 2010a).

Os guaxinins e os quatis, entre outras espécies silvestres, são classificados pelo Ministério da Saúde (MS) como animais de risco, mesmo quando domiciliados e/ou domesticados, uma vez que a patogenia da raiva não é bem conhecida nessas espécies animais (Brasil, 2006a). Os guaxinins, por sua vez, já são considerados como reservatórios pelo próprio MS (Brasil, 2006b).

A taxa de soropositividade de 5,4\% (4/74) para anticorpos antirrábicos foi detectada em carnívoros silvestres de vida livre na Reserva Privada do SESC-Pantanal, no Mato Grosso. Do total de animais amostrados, 13 eram mãos-peladas (Procyon cancrivorus), nos quais se verificou 7,7\% (1/13) de soroprevalência. Tais resultados ressaltam o risco que a raiva representa para a conservação dos carnívoros silvestres brasileiros e a possibilidade de esses animais atuarem como reservatório deste vírus. Sendo assim, planos de vigilância devem ser desenvolvidos para essas regiões, incluindo a identificação das cepas circulantes entre os carnívoros selvagens (Jorge et al., 2010b).

\section{Arboviroses}

Em 1942, a expressão arthropod-borne virus começou a ser utilizada para designar um grupo viral transmitido por meio de artrópodes aos hospedeiros vertebrados. No entanto, o termo arbovirus (arbovírus) foi oficialmente adotado somente duas décadas depois, por recomendação do Subcomitê Internacional para Nomenclatura Viral para designar vírus mantidos na natureza em ciclos que envolvem artrópodes hematófagos como vetores e vertebrados como hospedeiros (Pauvolid-Corrêa \& Varella, 2008). Os arbovírus estão incluídos nas famílias Asfarviridae, Bunyaviridae, Flaviviridae, Reoviridae, Rhabdoviridae e Togaviridae (Murphy et al., 1999).

A grande maioria das arboviroses são zoonoses relacionadas aos ambientes silvestres, o que faz com que as pessoas que frequentam esses ambientes sejam suas principais vítimas. No entanto, no Brasil, epidemias de algumas arboviroses como dengue, mayaro, oropouche e rocio têm surgido periodicamente nas cidades (Cruz et al., 2009).

No Brasil, dezenas de vírus da família Bunyaviridae foram isolados. Do ponto de vista epidemiológico, o mais importante deles é o bunyavirus Oropouche, 
do grupo sorológico Simbu, por causar extensas epidemias que acometem seres humanos na região amazônica. Este é superado apenas pelo dengue em número de casos notificados. O vírus Oropouche é causador de extensas e explosivas epidemias de doença febril aguda, de início abrupto, cujos sintomas habituais são: febre, cefaleia, mialgias, artralgias, anorexia, tonturas, calafrios e fotofobia (Figueiredo, 1999).

$\mathrm{O}$ vírus Jatobal é também do grupo sorológico Simbu e foi isolado em 1985 em Tucuruí, no estado do Pará, do sangue de um quati capturado, o que trouxe preocupação ante a possibilidade de esta espécie ser um hospedeiro desse vírus ainda desconhecido (Figueiredo \& Rosa, 1988; Figueiredo, 1999; Saeed et al., 2001). No entanto, nenhuma outra amostra do vírus Jatobal foi obtida desde o seu primeiro isolamento e, até então, não há evidências que o impliquem como um patógeno humano (Saeed et al., 2001).

Também faz parte da família Bunyaviridae o grupo Anopheles A (ANA). Um de seus membros, o Tacaiuma, é apontado como patógeno humano que causa uma síndrome febril aguda e acompanhada de mialgia nos indivíduos acometidos (Rosa et al., 1992).

Três outros vírus (Tucuruí, Caraipé e Arumateua) pertencentes ao grupo ANA foram isolados e caracterizados por Rosa et al. (1992) em mosquitos do grupo Anopheles (Nyssorhynchus) da área da usina hidrelétrica de Tucuruí, no estado do Pará, durante o período de 1984 a 1990. Outra amostra do Tucuruí também foi obtida no município de Balbina, no estado do Amazonas. Os testes de neutralização realizados em camundongos foram positivos somente para o soro de um quati, o único que neutralizou a amostra Tucuruí. Os autores afirmam a necessidade de estudos voltados à elucidação do ciclo biológico de manutenção desses agentes, principalmente no que diz respeito aos seus hospedeiros silvestres e sua possibilidade de causar doença em humanos e outros animais.

$\mathrm{O}$ vírus Ilhéus, um Flavivirus transmitido em um ciclo enzoótico entre pássaros e mosquitos, não está associado a doenças epidêmicas e foi apenas esporadicamente isolado de seres humanos. O quadro clínico da infecção humana varia desde formas assintomáticas até aquelas com sinais de envolvimento do sistema nervoso central, o que é sugestivo de encefalite. Mais comumente há quadros ligeiramente febris, acompanhados por cefaleia, mialgia, artralgia e fotofobia, sintomas que podem resultar em diagnóstico clínico de dengue, encefalite de Saint Louis, febre amarela ou gripe (Johnson et al., 2007).

Em um estudo com animais silvestres do Parque Ecológico do Tietê (PET), no município de São Paulo, foram isoladas duas cepas do vírus Ilhéus em sangue de aves e detectados anticorpos inibidores de hemaglutinação em 3,7\% (1/27) dos quatis, que são animais nativos do parque. O PET recebe e mantém animais provenientes de diversas regiões do país, além disso há a presença de culicídeos potencialmente vetores e de aves migratórias, elementos que podem ser considerados fatores de risco para a introdução, manutenção e transmissão de arboviroses (Pereira et al., 2001). 
Pereira et al. (2001) consideraram a patogenicidade do vírus, a confirmação de sua circulação no PET, a inserção do parque em uma zona urbana densamente povoada e o uso de suas instalações para fins de lazer pela população local como fatores de risco de infecção para as pessoas que o frequentam ou residem em suas proximidades.

O alphavirus Mayaro (família Togaviridae) é responsável por epidemias de doenças exantemáticas febris na Amazônia e em outras regiões da América Latina (Thoisy et al., 2003). A febre de Mayaro é uma doença aguda não fatal, semelhante ao dengue, caracterizada por cefaleia frontal, dor epigástrica, mialgias, artralgias incapacitantes, exantema máculo-papular, febre, calafrios, fotofobia, náusea e vertigem. A dor nas articulações pode persistir por vários meses (Coimbra et al., 2007).

Um inquérito sorológico para a detecção de anticorpos contra este agente foi realizado por Thoisy et al. (2003), na Guiana Francesa, em 579 mamíferos silvestres florestais pertencentes a 28 espécies. A soroprevalência encontrada nos juparás foi de $11 \%(1 / 9)$. Apesar de as informações sobre a incidência, a susceptibilidade de hospedeiros e a patogenicidade do vírus Mayaro em animais silvestres serem limitadas, a presença de anticorpos mostra que um antígeno específico ou intimamente relacionado sorologicamente esteve ou está presente.

\section{Tripanossomose}

O Trypanosoma cruzi, agente causador da doença de Chagas, infecta de 8 a 11 milhões de pessoas na América Latina (Maloney et al., 2010). Sua transmissão para o homem ocorre por meio de um vetor triatomídeo que se infectou ao sugar sangue de mamíferos infectados (Brasil, 2010b).

A forma humana da doença tem uma apresentação clínica variável. Após a infecção, há uma fase aguda com parasitemia detectável com relativa facilidade por meio de exame direto sanguíneo. Na maioria dos pacientes, essa fase passa despercebida em virtude da escassez ou ausência de sintomas. No entanto, cerca de $5 \%$ a $10 \%$ dos pacientes sintomáticos podem morrer por encefalomielite ou insuficiência cardíaca grave caso não sejam tratados (Sánchez-Guillén et al., 2006).

A forma crônica caracteriza-se por um período assintomático que ocorre após a fase aguda (quando presente). Os pacientes não apresentam quadros clínicos uniformes. Enquanto elevado percentual nada sofrerá no decorrer de sua vida, outros poderão apresentar cardiopatia discreta, cardiopatia grave arritmogênica ou sofrer morte súbita. A forma cardíaca é a mais grave das modalidades crônicas por causa do comprometimento progressivo da função miocárdica. $\mathrm{O}$ megaesôfago e o megacólon são as manifestações digestivas mais importantes associadas à lesão da inervação intrínseca dos correspondentes órgãos (Ferreira et al., 2003).

Nos Estados Unidos, apesar de o T. cruzi ser endêmico em algumas espécies de animais silvestres, as infecções autóctones humanas são raramente documentadas (Maloney et al., 2010). 
Em 1968, Ferriolli Filho e Barreto isolaram o parasito de um quati capturado no município de Morro Grande, São Paulo, por xenodiagnóstico em camundongos. $\mathrm{O}$ parasito mostrou-se patogênico para os camundongos jovens, causando infecção grave com alta taxa de letalidade. Também foi encontrado nos cultivos e infectou quatro espécies de triatomíneos utilizados no experimento, assim como foi encontrado em triatomíneos da espécie Panstrongylus megistus capturados de uma árvore onde o quati infectado se aninhava. Tais resultados levaram os autores a considerar o quati como um hospedeiro natural do parasito.

Pung et al. (1995) conduziram uma pesquisa sobre a prevalência da infecção de T. cruzi em gambás e guaxinins silvestres de diversas cidades do estado da Georgia, nos Estados Unidos. Amostras de sangue de 54 guaxinins foram inoculadas em meio de cultura, possibilitando o encontro de epimastigotas em 22,2\% (12/54) delas. A forma tripomastigota foi observada no sangue de um dos guaxinins.

Considerando que os guaxinins ( $P$. lotor) são reservatórios para o T. cruzi, Hancock et al. (2005) realizaram uma pesquisa sorológica ao longo de três anos (2000 a 2002) no condado de Fairfax, Virginia, Estados Unidos, visando determinar a prevalência de anticorpos anti-T. cruzi nesta espécie e encontraram 33\% (154/464) de positividade por meio de imunofluorescência indireta (IFAT), considerando todo o período experimental. Anualmente, as prevalências foram de 37\% (49/132) em $2000,16 \%$ (19/120) em 2001 e 41\% (86/212) em 2002. Os resultados indicaram a frequente exposição dos guaxinins ao T. cruzi.

No Brasil, Herrera et al. (2008), ao estudarem a infecção do T. cruzi em quatis do Pantanal do Mato Grosso do Sul nos períodos de 2000 a 2001 e 2005 a 2007, demonstraram que o ciclo de transmissão do T. cruzi entre os quatis daquela região parece estar bem estabelecido. Para isso, utilizaram os testes IFAT, hemocultura e detecção molecular por meio da reação em cadeia pela polimerase (PCR).

As taxas gerais de soroprevalência encontradas por Herrera et al. (2008) foram de $61 \%$ (75/123) durante o primeiro período e de 74,3\% (26/35) no segundo; as taxas de parasitemia nas hemoculturas durante os dois períodos foram, respectivamente, de $20 \%(15 / 75)$ e $73,1 \%$ (18/26). As três principais linhagens de T. cruzi (TCI, TCII e Z3) foram detectadas na forma de infecções únicas - TCI (28,6\%), TCII (32,1\%) e Z3 (7,1\%) - ou infecções mistas - TCI/TCII (10,7\%) e $\mathrm{TCI} / \mathrm{Z3}(3,6 \%$ ) -, indicando que os quatis podem desempenhar um papel importante na manutenção e dispersão das subpopulações principais de $T$. cruzi na região do Pantanal. Neste estudo também foi detectada a infecção única por T. rangeli em um macho adulto.

Em estudo mais recente, Maloney et al. (2010), pesquisando a soroprevalência de anticorpos reativos para o $T$. cruzi em guaxinins por meio de IFAT, encontraram soropositividade em animais de nove das dez cidades amostradas do Tennessee, Estados Unidos, em um percentual de 29,2\% (206/706) dos animais. A zona rural apresentou índices mais elevados $(35,1 \%)$ que os das áreas suburbanas $(23,1 \%)$. Considerando-se os anos de estudo, os resultados foram: $28,8 \%(53 / 184)$ 
em três cidades, em 2005; 28\% (67/239) em sete cidades, em 2006 e 30,4\% (86/283) em sete cidades, em 2007.

Leishmaniose

$\mathrm{Na}$ América Latina, as espécies de leishmanias causam duas doenças com diferentes formas clínicas nos seres humanos: a leishmaniose tegumentar americana (LTA) que inclui as formas cutânea, mucocutânea ou cutâneo-difusa, causadoras de graves lesões mutilantes (Brasil, 2007), e a leishmaniose visceral americana (LVA) ou Calazar, enfermidade grave e crônica que infecta órgãos internos como baço, fígado, linfonodos e medula óssea, cuja letalidade pode atingir 100\% quando o tratamento adequado não é instituído. Em ambas as formas clínicas, os agentes são transmitidos por insetos denominados flebotomíneos (Camargo \& Langoni, 2006).

A LVA tem como um de seus agentes causadores a L. chagasi, que atualmente tem os marsupiais e as raposas reconhecidos como seus hospedeiros silvestres. Tais animais, em razão de seus hábitos sinantrópicos, permitem a conexão entre os ciclos silvestre e doméstico da doença, considerando-se que o cão doméstico está associado ao seu ciclo doméstico, portanto hospeda o referido agente e infecta os vetores (Gontijo \& Melo, 2004).

As infecções por leishmanias que causam a LTA foram descritas em várias espécies silvestres, incluindo roedores e macacos de diferentes gêneros, preguiças (Choloepus didactylus), tamanduás (Tamandua tetradactyla), gambás (Didelphis albiventris), pacas (Agouti paca), tatus (Dasypus novemcinctus) e inclusive quatis (Nasua nasua). Embora o papel desempenhado por estes animais ainda não tenha sido bem definido, as evidências encontradas indicam a possibilidade de que alguns deles representem reservatórios de leishmanias (Brasil, 2007).

Na Guiana Francesa, foi encontrada Leishmania spp. em 13,5\% dos indivíduos de um grupo de 74 mamíferos de várias ordens e espécies. Sete juparás integravam este grupo, o qual apresentou prevalência de 14,28\% (1/7) (Pajot et al., 1982).

No Equador, Mimori et al. (1989) identificaram, por meio de eletroforese isoenzimática e anticorpos monoclonais específicos, três cepas de L. amazonensis, obtidas de amostras de fígado e baço de três animais silvestres: um esquilo (Sciurus vulgaris), um tamanduá (Tamandua tetradactyla) e um jupará (Potos flavus).

No Brasil, em 1989, Lainson et al. descreveram a presença de L. (Viannia) shawi em flebótomos da espécie $L u$. whitmani e em macacos, preguiças e, até mesmo, em quatis de uma floresta primária no estado do Pará.

Em 1993, Grimaldi Junior \& Tesh citaram o quati como reservatório da $L$. panamensis e $L$. (V.) shawi, sendo esta última detectada no Brasil; fizeram também menção ao jupará como reservatório da L. panamensis e L. amazonensis. Marzochi \& Marzochi (1994) também relataram a associação do quati, entre outros animais silvestres amazônicos, com a $L$. (V.) shawi. 
A infecção por Leishmania spp. foi investigada em 60 mamíferos silvestres do Parque do Ingá, no município de Maringá, utilizando-se para sorologia o teste de aglutinação direta (DAT) com antígeno de $L$. (V.) braziliensis. Títulos de anticorpos $\geq$ a 10 foram detectados em 51,6\% (31/60) do total dos animais, sendo observado em $50 \%$ (1/2) dos mãos-peladas e 50\% (1/2) dos quatis (Voltarelli et al., 2009). Segundo os autores, tais evidências sorológicas sugerem que estes mamíferos têm um importante papel na transmissão da leishmaniose tegumentar no noroeste do Paraná.

Lainson (2010) considera que $L$. (V) shawi encontra-se distribuída em várias áreas da amazônia brasileira, ao passo que $L$. (V.) panamensis é encontrada no Panamá, Colômbia, Costa Rica, Equador, Honduras, Nicarágua e Venezuela. Relata que, apesar de o principal hospedeiro da $L$. (V.) panamensis ser a preguiça (Choloepus hoffmanni), esse parasito também é reportado em animais arbóreos, incluindo alguns procionídeos como o Bassaricyon gabbi, o $N$. nasua (quati) e o $P$. flavus (jupará). Cães de caça e humanos muitas vezes são acometidos, tornando-se hospedeiros com lesões de pele.

Embora estudos demonstrem o possível envolvimento dos carnívoros selvagens na epidemiologia das leishmanioses, é necessário um maior aprofundamento para esclarecer os papéis desempenhados por essas espécies e o potencial impacto das diferentes espécies de Leishmania spp. sobre esses animais (Jorge et al., 2010a).

\section{Leptospirose}

A leptospirose é uma doença infecciosa febril, de início abrupto, cujo espectro pode variar desde um processo inaparente até formas graves que causam icterícia, insuficiência renal, hemorragias ou mesmo a morte. Qualquer sorovar pode determinar as diversas formas de apresentação clínica no homem; no Brasil, os sorovares Icterohaemorrhagiae e Copenhageni frequentemente estão relacionados aos casos mais graves (Brasil, 2010c).

Manifestando ou não sinais clínicos, quase todas as espécies domésticas e silvestres podem adquirir leptospirose e, consequentemente, tornar-se portadoras e eliminar o agente etiológico no ambiente. Quando se trata de animais domésticos, a eliminação por meio da urina pode ocorrer por períodos que variam de poucas semanas a vários meses ou, no caso dos roedores, por toda a vida (Girio et al., 2004). Já nos animais silvestres, os estudos epidemiológicos sobre leptospirose ainda são bastante escassos, inclusive no Brasil (Silva et al., 2010).

Souza-Junior et al. (2006) verificaram soroprevalência de 11,66\% (54/463) em animais silvestres resgatados durante o enchimento do lago de uma usina hidrelétrica no estado do Tocantins, somente nos quatis o valor foi mais elevado, atingindo $12,9 \%$ (4/31) com títulos variando de 1/100 a 1/1.600. Os sorovares Fluminense e Javanica foram detectados nos quatis pesquisados. Os autores alertam para a importância dos achados, em razão da vulnerabilidade quanto 
à infecção por $L$. interrogans das populações humanas e animais que estavam ou venham a estar com esses animais.

Girio et al. (2004) pesquisaram a prevalência de 24 sorovares de Leptospira spp. em soros sanguíneos de 315 indivíduos de diversas espécies de animais silvestres e domésticos da região de Nhecolândia, no município de Corumbá, Mato Grosso do Sul, por meio da prova de soroaglutinação microscópica. Foram considerados como soropositivos animais com título mínimo de 1:100 e, do total de amostras, 20,3\% (64/315) foram reagentes ao menos contra um sorovar de Leptospira patogênica. Em nenhuma das nove amostras oriundas de quatis ( $N$. Nasua) ocorreu reação contra os sorovares testados.

Na mesma região da Nhecolândia, cinco anos depois Vieira (2009) realizou um estudo de soroprevalência utilizando testes de soroaglutinação microscópica e PCR em 164 mamíferos silvestres, dos quais 55 eram quatis. A prevalência geral encontrada, envolvendo todas as espécies, foi de $22,9 \%$ na soroaglutinação e $26,6 \%$ na PCR. Nos quatis, a prevalência detectada por soroaglutinação e por PCR foi, respectivamente, de $34,1 \%$ e $28,1 \%$, sendo predominante o sorovar Pomona (38,5\%). A circulação da Leptospira spp entre os animais silvestres da região foi demonstrada e o $N$. nasua foi apontado como hospedeiro acidental do citado sorovar, portanto poderia desenvolver a doença e disseminar o agente.

Quatis de cativeiro provenientes de Sorocaba, Botucatu e São José dos Campos foram alvo de um estudo de soroprevalência realizado por Langoni et al. (2009), por meio do teste de aglutinação microscópica, utilizando 28 sorovares. Os anticorpos foram detectados em 52,9\% (9/17) dos animais, com títulos variando de $1 / 100$ até maior que $1 / 3.200$. Foram positivas $61,5 \%$ (8/13) das amostras de Sorocaba, envolvendo isoladamente os sorovares Copenhageni (2/8), Andamana (1/8), Shermani (2/8) e Wolfii (1/8) e duas coaglutinações, uma de Hebdomadis e Wolfii (1/8) e outra de Hebdomadis, Hardjo e Wolfii (1/8). A única amostra coletada em São José dos Campos foi positiva (sorovar Pyrogenes) e as três de Botucatu foram soronegativas. A presença da infecção em quatis de cativeiro, mesmo assintomáticos, reforça a possibilidade de animais silvestres cativos serem infectados e tornarem-se reservatórios.

Mamíferos selvagens neotropicais do Zoológico de Aracaju, Sergipe, também foram testados por meio da técnica de soroaglutinação microscópica, utilizando-se 24 sorovares patogênicos e dois saprófitas. Dentre os 32 mamíferos, 8 eram procionídeos, sendo 6 mãos-peladas e 2 quatis. A soropositividade geral verificada foi de $12,5 \%$ (4/32), sendo $16,7 \%$ (1/6) nos mãos-peladas e ausente nos quatis. O sorovar Copenhageni foi o único detectado nos mãos-peladas. Como este membro do sorogrupo Icterohaemorragiae tem como hospedeiros de manutenção roedores sinantrópicos, particularmente a ratazana (Rattus norvergicus), foi sugerida a presença de roedores como possível reservatório no ambiente do Zoológico de Aracaju (Pimentel et al., 2009). 


\section{Doenças fúngicas}

Conforme o tipo de infecção, as principais micoses podem ser assim distribuídas: superficiais e cutâneas, destacando-se as dermatofitoses; subcutâneas, destacando-se a esporotricose, e sistêmicas. Este último tipo se subdivide entre as causadas por fungos dimórficos (blastomicose, coccidioidomicose, histoplasmose, paracoccidioidomicose) e as causadas por fungos oportunistas (candidíase, aspergilose, mucormicose e criptococose) (Lacaz et al., 2002).

Pouca atenção tem sido dada à ocorrência natural das micoses em animais selvagens da América Latina (Costa et al., 1995b; Richini-Pereira et al., 2008). Não obstante, alguns animais selvagens podem estar envolvidos na epidemiologia de alguns patógenos fúngicos, como Sporothrix schenckii e Histoplasma capsulatum (Costa et al., 1995b). Existem relatos de Paracoccidioides brasiliensis (Costa et al., 1995a; Costa et al., 1995b; Richini-Pereira et al., 2008), H. capsulatum, S. schenckii e fungos dermatófitos (Findlay et al., 1971; Costa et al., 1994) nos procionídeos.

A paracoccidioidomicose é uma micose sistêmica causada pelo fungo dimórfico Paracoccidioides brasiliensis, constituindo-se na micose sistêmica mais importante e prevalente na América Latina, principalmente no Brasil, Colômbia e Venezuela (Wanke \& Londero, 1994). Uma grande variedade de mamíferos pode ser infectada, tendo sido descritas infecções naturais por testes intradérmicos em equinos, bovinos e em macacos de vida livre. A doença é observada em humanos e, recentemente, foram relatados casos em cães. O tatu de nove bandas (Dasypus novemcinctus) vem sendo considerado reservatório do fungo em determinadas áreas endêmicas, pois apresenta altos índices de isolamento fúngico (RichiniPereira et al., 2008).

A doença provoca um impacto social significativo na maioria dos países latino-americanos, uma vez que afeta principalmente os trabalhadores rurais em fase produtiva. Seu tratamento é frequentemente difícil e longo, necessitando muitas vezes de internação e os custos têm se tornado cada vez mais elevados (Wanke \& Londero, 1994).

O DNA do Paracoccidioides brasiliensis foi detectado em órgãos de várias espécies de animais selvagens mortos por atropelamento em rodovias do estado de São Paulo. Dentre esses, havia dois guaxinins (Procyon cancrivorus) cujo DNA fúngico foi detectado em tecido pulmonar (Richini-Pereira et al., 2008). Testes de hipersensibilidade tardia à paracoccidioidina realizados em 96 animais do Zoológico de São Paulo indicaram 22,4\% de positividade naqueles de hábitos arborícolas e $82,9 \%$ nos de hábitos terrestres. Entre os 37 quatis (Nasua nasua) submetidos ao teste, $35(94,6 \%)$ revelaram-se positivos (Costa et al., 1995a; Costa et al., 1995b).

Animais de hábitos terrestres, especialmente o quati, são apontados como importantes agentes na epidemiologia da paracoccidioidomicose, uma vez que atuam como reservatório natural deste fungo. Seus hábitos permitem facilmente a infecção pelo fungo e eventualmente contaminam o solo com suas excreções 
e secreções. Mesmo depois de mortos suas carcaças podem contaminar o meio ambiente, contribuindo, assim, para a perpetuação desta doença (Costa et al., 1995a; Costa et al., 1995b).

Uma outra doença fúngica de interesse é a esporotricose, micose subcutânea causada pelo fungo dimórfico Sporothrix schenckii, que acomete o homem e os animais, principalmente o gato. A apresentação mais comum é a cutânea, porém em indivíduos imunodeprimidos pode evoluir para infecção sistêmica (Costa et al., 1994; Pérez \& Carrasco, 2000).

Em um estudo epidemiológico realizado com 96 animais do Zoológico de São Paulo, foi detectado um índice de positividade para esporotriquina de 30,2\%. Do total de animais, 37 eram quatis, dos quais $24(64,8 \%)$ apresentaram resultados positivos (Costa et al., 1994).

A histoplasmose é uma infecção fúngica causada pelo Histoplasma capsulatum, um fungo que vive no solo úmido com matéria orgânica abundante. Afeta o homem e outras espécies como o cão e o gato. As infecções tendem a ser sistêmicas, principalmente em animais jovens (Pérez \& Carrasco, 2000), sendo a segunda micose sistêmica mais prevalente no Brasil, logo atrás da paracoccidioidomicose (Costa et al., 1994). No mesmo estudo citado anteriormente sobre esporotricose, Costa et al. (1994) observaram que 44,8\% dos 96 animais testados no Zoológico de São Paulo foram positivos para histoplasmina, enquanto nos procionídeos (quatis) este valor subiu para $86,5 \%$.

A dermatofitose é uma das micoses zoonóticas mais comuns em felinos, caninos, bovinos e equinos. É causada por várias espécies de três gêneros de fungos: Microsporum, Trichophyton e Epidermophyton. A infecção fúngica por dermatófitos geralmente está restrita ao estrato córneo da epiderme, folículos pilosos, pêlos e unhas (Pérez \& Carrasco, 2000).

Dermatófitos geofílicos, como o M. gypseum, normalmente habitam o solo, enquanto os zoofilicos, como o M. canis, se adaptaram aos animais, sendo raramente encontrados no solo (Pérez \& Carrasco, 2000). Findlay et al. (1971) mencionam a infecção causada pelo M. gypseum em um quati de 2 meses de idade, no zoológico de Pretória, África do Sul, cujas lesões cutâneas já se encontravam distribuídas nas regiões lombar e inguinal, cauda, períneo e membros pélvicos.

\section{CONSIDERAÇÕES FINAIS}

Os procionídeos podem ser acometidos por doenças infectocontagiosas, assim como os animais domésticos. Tais doenças podem ser mantidas nas populações silvestres de procionídeos de forma endêmica pela transmissão do agente entre seus indivíduos ou podem ser adquiridas por meio do contato com os animais domésticos ou insetos vetores. Algumas das doenças endêmicas mantidas dentro das áreas silvestres podem ter um significado importante no controle do tamanho das populações dos procionídeos, na medida em que podem causar uma 
reduzida, porém constante, ocorrência de óbitos. Já as doenças adquiridas dos animais domésticos, seja pelo contato peridomiciliar ou domiciliar, podem chegar aos procionídeos na forma de epidemias, causando reduções significativas na quantidade de animais.

O sentido inverso na transmissão de doenças também é verificado, ou seja, os procionídeos podem servir de reservatórios ou transmitir doenças aos animais e seres humanos que invadem seus habitats ou por meio do contato ou convívio com estes no ambiente urbano. Dessa forma, se por um lado os procionídeos são importantes para a manutenção da biodiversidade, por meio da dispersão de sementes e controle das populações de suas presas e predadores, também podem representar importante papel na manutenção e transmissão de doenças infectocontagiosas para os animais domésticos e o homem. No entanto, devemos refletir se estes animais, assim como os de outras espécies silvestres, devem ser considerados vilões ou vítimas de todo esse processo desenfreado de antropização que, ao fragmentar cada vez mais os ambientes silvestres, tende a aumentar o contato entre esses animais e o ambiente urbano, deixando todos expostos às consequências desse convívio.

\section{REFERÊNCIAS}

1. Acha PN, Szyfres B. Zoonosis y enfermedades transmisibles comunes al hombre y a los animales. Organización Panamericana de la Salud (OPAS). Washington D.C., 2003.

2. Aguirre AA. Wild canids as sentinels of ecological health: a conservation medicine perspective. Parasit Vectors 2: 1-8, 2009.

3. Alves-Costa CP, Eterovick PC. Seed dispersal services by coatis (Nasuanasua, Procyonidae) and their redundancy with other frugivores in southeastern Brazil. Acta Oecol 32: 77-92, 2007.

4. Aréchiga-Ceballos N, Velasco-Villa A, Shi M, Flores-Chávez S, Barrón B, Cuevas-Domínguez E, González-Origel A, Aguilar-Setién A. New rabies virus variant found during an epizootic in white-nosed coatis from the Yucatan Peninsula. Epidemiol Infect 138: 1586-1589, 2010.

5. Blanton JD, Palmer D, Christian KA, Rupprecht CE. Rabies surveillance in the United States during 2007. J Am Vet Med Assoc 233: 884-897, 2008.

6. Brasil. Ministério da Saúde. Aspectos clínicos e laboratoriais. Informações Técnicas. 2006a. Disponível em: <http://portal.saude.gov.br/portal/saude/profissional/visualizar_texto. cfm?idtxt=32021\&janela=1>. Acesso em 25.09.2010.

7. Brasil. Ministério da Saúde. Aspectos epidemiológicos. Informações Técnicas. 2006b. Disponível em: <http://portal. saude.gov.br/portal/saude/profissional/visualizar_texto.cfm?idtxt=32022> Acesso em 25.09.2010.

8. Brasil. Ministério da Saúde. Manual de vigilância da leishmaniose tegumentar americana. Ministério da Saúde. Brasília, 2007.

9. Brasil. Ministério da Agricultura, Pecuária e Abastecimento. Transmissores. Plano Nacional de Controle da Raiva dos Herbívoros. 2010a. Disponível em: <http://www.agricultura. gov.br/pls/portal/docs/PAGE/MAPA/PROGRAMAS/AREA_ANIMAL/CRHE/PNCRH/ TRANSMISSORES.PDF>. Acesso em 26.10.2010.

10. Brasil. Ministério da Saúde. Aspectos epidemiológicos. Doença de Chagas. Informações Técnicas. 2010b. Disponível em: <http://portal.saude.gov.br/portal/arquivos/pdf/gve_7ed_web_atual_ doenca de chagas.pdf $>$. Acesso em 26.10.2010.

11. Brasil. Ministério da Saúde. Secretaria de Vigilância em Saúde. Leptospirose. Guia de Vigilância Epidemiológica. Ministério da Saúde. Brasília, 2010c. Disponível em: <http://portal.saude.gov. br?portal/arquivos/pdf/gve_7ed_web_atual.pdf $>$. Acesso em 30.10.2010. 
12. Camargo LB, Langoni H. Impact of leishmaniasis on public health. J Venom Anim Toxins incl Trop Dis 12: 527-548, 2006.

13. Coimbra TL, Santos CL, Suzuki A, Petrella SM, Bisordi I, Nagamori AH, Marti AT, Santos RN, Fialho DM, Lavigne S, Buzzar MR, Rocco IM. Mayaro virus: imported cases of human infection in São Paulo state, Brazil. Rev Inst Med Trop São Paulo 49: 221-224, 2007.

14. Costa EO, Diniz LS, Netto CF, Arruda C, Dagli ML. Epidemiological study of sporotrichosis and histoplasmosis in captive Latin American wild mammals, São Paulo, Brazil. Mycopathologia 125: 19-22, 1994.

15. Costa EO, Diniz LSM, Fava-Netto C. The prevalence of positive intradermal reactions to paracoccidioidin in domestic and wild animals in São Paulo, Brazil. Vet Res Commun 19: 127-130, 1995a.

16. Costa EO, Diniz LS, Netto CF, Arruda C, Dagli ML. Delayed hypersensitivity test with paracoccidioidin in captive Latin American wild mammals. J Med Vet Mycol 33: 39-42, 1995 b.

17. Cruz ACR, Prazeres ASC, Gama EC, De Lima MF, Azevedo RSS, Casseb LMN, Neto JPN, Martins LC, Chiang JO, Rodrigues SG, Vasconcelos PFC. Vigilância sorológica para arbovírus em Juruti, Pará, Brasil. Cad Saúde Pública 25: 2517-2523, 2009.

18. Dantas-Torres F, Ferreira DRA, Melo LM, Lima PCP, Siqueira DB, Albuquerque LCR, Melo AV, Ramos JAC. Ticks on captive and free-living wild animals in Northeastern Brazil. Exp Appl Acarol 50: 181-189, 2010.

19. Evans RH. Baylisascaris procyonis (Nematoda: Ascaridae) in Raccoons (Procyon lotor) in Orange County, California. Vector Borne Zoonotic Dis 1: 239-242, 2001.

20. Ferreira MS, Rocha A, Luquetti AO. Doença de Chagas. In: Cimerman S, Cimerman B. Medicina tropical. Atheneu. São Paulo, 2003. p.690.

21. Ferriolli Filho F, Barreto MP. Estudos sobre reservatório e vetores silvestres do Trypanosoma cruzi. XXIX - Infecção natural da Nasua nasua solitaria Schinz, 1821 pelo T. cruzi. Rev Inst Med Trop São Paulo 10: 354-363, 1968.

22. Figueiredo LTM. Vírus brasileiros da família Bunyaviridae. Medicina 32: 154-158, 1999.

23. Figueiredo LTM, Rosa APAT. Jatobal virus antigenic characterization by ELISA and neutralization test using EIA as indicator, on tissue culture. Mem Inst Oswaldo Cruz 83: 161-164, 1988.

24. Findlay GH, Roux HF, Simson IW. Uncontrolled Microsporum gypseum infection in a new born mammal. Br J Dermatol 85: 87-93, 1971.

25. Girio RJS, Pereira FLG, Marchiori Filho M, Mathias LA, Herreira RCP, Alessi AC, Girio TMS. Pesquisa de anticorpos contra Leptospira spp. em animais silvestres e em estado feral da região de Nhecolândia, Mato Grosso do Sul, Brasil: utilização da técnica de imunohistoquímica para deteç̧ão do agente. Cienc Rural 34: 165-169, 2004.

26. Grimaldi Junior G, Tesh RB. Leishmaniases of the New World: current concepts and implications for future research. Clin Microbial Rev 6: 230-250, 1993.

27. Gontijo CMF, Melo MN. Leishmaniose visceral no Brasil: quadro atual, desafios e perspectivas. Rev Bras Epidemiol 7: 338-349, 2004.

28. Hancock K, Zajak AM, Pung OJ, Elvinger F, Rosypal AC, Lindsay DS. Prevalence of antibodies to Trypanosoma cruzi in raccoons (Procyon lotor) from an urban area of northern Virginia. J Parasitol 91: 470-472, 2005.

29. Herrera HM, Lisboa CV, Pinho AP, Olifiers N, Bianchi RC, Rocha FL, Mourão GM, Jansen AM. The coati (Nasua nasua, Carnivora, Procyonidae) as a reservoir host for the main lineages of Trypanosoma cruzi in the Pantanal region, Brazil. Trans R Soc Trop Med Hyg 102: 1133-1139, 2008.

30. Johnson BW, Cruz C, Felices V, Espinoza WR, Manock SR, Guevara C, Olson JG, Kochel TJ. Ilheus virus isolate from a human, Ecuador. Emerg Infect Dis 13: 956-958, 2007.

31. Jorge RSP, Rocha FL, May Junior JA, Morato RG. Ocorrência de patógenos em carnívoros selvagens brasileiros e suas implicações para a conservação e saúde pública. Oecol Aust 14: 686-710, 2010a.

32. Jorge RSP, Pereira MS, Morato RGA, Scheffer KC, Carnieli Jr P, Ferreira F, Furtado MM, Kashivakura CK, Silveira L, Jacomo ATA, Lima ES, de Paula RC, May-Junior JA. Detection of rabies virus antibodies in brazilian free-ranging wild carnivores. J Wildlife Dis 46: 1310-1315, $2010 \mathrm{~b}$. 
33. Kaplan C, Turner GS, Warrel DA. Rabies: the facts. Oxford University Press. Oxford, 1986. p.126.

34. Koepfli KP, Gompper ME, Eizirik E, Ho CC, Linden L, Maldonado JE, Wayne RK. Phylogeny of the Procyonidae (Mammalia: Carnivora): Molecules, morphology and the Great American Interchange. Mol Phylogenet Evol 43: 1076-1095, 2007.

35. Kollias G, Abou-Madi N. Procyonids and Mustelids In: West G, Heard D, Caulkett N. Zoo Animal \& Wildlife immobilization and Anesthesia. Blackwell Publishing. Ames, 2007. p.718.

36. Lacaz CS, Porto E, Martins JEC, Vaccari EMH, Melo NT. Tratado de micologia médica. 9.ed. Sarvier. São Paulo, 2002. p.1104.

37. Lainson R. The Neotropical leishmania species: a brief historical review of their discovery, ecology and taxonomy. Rev Pan-Amaz Saúde 1: 13-32, 2010.

38. Lainson R, Braga RR, Souza AA, Pôvoa MM, Ishikawa EA, Silveira FT. Leishmania (Viannia) shawi sp., a parasite of monkeys, sloths and procyonids in Amazonian Brazil. Ann Parasitol Hum Comp 64: 200-207, 1989.

39. Langoni H, Kawaguchi MF, Oshika JC, Silva RC, Teixeira CR. Leptospira spp. Antibodies in captive coatis (Nasua nasua STORR, 1780) (Carnivora: Procyonidae). J Venom Anim Toxins incl Trop Dis 15: 762-767, 2009.

40. Maloney J, Newsome A, Huang J, Kirby J, Kranz M, Wateska A, Dunlap B, Yabsley MJ, Dunn JR, Jones TF, Moncayo AC. Seroprevalence of Trypanosoma cruzi in raccoons from Tennessee. $J$ Parasitol 96: 353-358, 2010.

41. Marzochi MCA, Marzochi KBF. Tegumentary and visceral leishmaniases in Brazil - emerging anthropozoonosis and possibilities for their control. Cad Saúde Pública 10: 359-375, 1994.

42. Milanelo L, Moreira MB, Fitorra LS, Petri BSS, Alves M, Saltos AC. Occurrence of parasitism by Dioctophyma renale in ringtailed coatis (Nasua nasua) of the Tiete Ecological Park, São Paulo, Brazil. Pesq Vet Bras 29: 959-962, 2009.

43. Mimori T, Grimaldi Junior G, Kreutzer RD, Gomez EA, Mcmahon-Pratt D, Tesh RB, Hashiguchi Y. Identification, using isoenzime electrofhoresis and monoclonal antibodies, of Leishmania isolated from humans and wild animals of Ecuador. Am J Trop Med Hyg 40: 154-158, 1989.

44. Murphy FA, Gibbs EPJ, Horzinek MC, Studdert MJ. Veterinary virology. Academic Press. San Diego, 1999. p.629.

45. Pajot FX, Le Pont F, Gentile B, Besnard R. Epidemiology of leishmaniasis in French Guiana. Trans R Soc Trop Med Hyg 76: 112-113, 1982.

46. Pauvolid-Corrêa A, Varella RB. Aspectos epidemiológicos da Febre do Oeste do Nilo. Rev Bras Epidemiol 11: 463-472, 2008.

47. Pereira LE, Suzuki A, Coimbra TLM, Souza RP, Chamelet ELB. Arbovírus ilheus em aves silvestres (Sporophila caerulescens e Molothrus bonariensis). Rev Saúde Pública 35: 119-123, 2001.

48. Pérez J, Carrasco L. Diagnóstico histopatológico de micosis en patología veterinária. Rev Iberoam Micol 17: 18-22, 2000.

49. Pimentel JS, Gennari SM, Dubey JP, Marvulo MFV, Vasconcellos SA, Morais ZM, Silva JCR, Neto JE. Inquérito sorológico para toxoplasmose e leptospirose em mamíferos selvagens neotropicais do Zoológico de Aracaju, Sergipe. Pesq Vet Bras 29: 1009-1014, 2009.

50. Pung OJ, Banks CW, Jones DN, Krissinger MW. Trypanosoma cruzi in wild raccoons, opossums, and triatomine bugs in Southeast Georgia, U.S.A. J Parasitol 81: 324-326, 1995.

51. Richini-Pereira VB, Bosco SG, Griese J, Theodoro RC, Macoris SAG, Silva RJ, Barrozo L, Tavares P, Zancope-Oliveira RM, Bagagli E. Molecular detection of Paracoccidioides brasiliensis in road-killed wild animals. Med Mycol 46: 35-40, 2008.

52. Rodrigues AFSF, Daemon E, Massard CL. Ectoparasites of Nasua nasua (Carnivora, Procyonidae) from an urban forest in Southeastern Brazil. Arq Bras Med Vet Zootec 58: 969-971, 2006.

53. Rosa JFST, Rosa APAT, Dégallier N, Vasconcelos PFC. Caracterização e relacionamento antigênico de três novos Bunyavirus no grupo Anopheles A (Bunyaviridae) dos arbovirus. Rev Saúde Pública 26: $173-178,1992$.

54. Rosatte R, Wandeler A, Muldoon F, Campbell D. Porcupine quills in raccoons as an indicator of rabies, distemper, or both diseases: disease management implications. Can Vet J 48: 299-300, 2007. 
55. Saeed MF, Wang H, Suderman M, Beasley DW, Rosa AT, Li L, Shope RE, Tesh RB, Barret AD. Jatobal virus is a reassortant containing the small RNA of Oropouche virus. Virus Res 77: 25-30, 2001.

56. Sánchez-Guillén MC, López-Colombo A, Ordóñez-Toquero G, Gomez-Albino I, Ramos-Jimenez J, Torres-Rasgado E, Salgado-Rosas H, Romero-Díaz M, Pulido-Pérez P, Pérez-Fuentes R. Clinical forms of Trypanosoma cruzi infected individuals in the chronic phase of Chagas' disease in Puebla, Mexico. Mem Inst Oswaldo Cruz 101: 733-739, 20.

57. Silva CS, Gírio RJS, Guerra Neto G, Brich M, Santana LAS, Amâncio FH, Mariani JR, Wessort PMF. Anticorpos anti-Leptospira spp. em animais selvagens do zoológico municipal de Ribeirão Preto, estado de São Paulo, Brasil. Braz J Vet Res Anim Sci 47: 237-242, 2010.

58. Smith JS, Yager PA, Baer GM. A rapid fluorescent focus inhibition test (RFFIT) for determining rabies virus-neutralizing antibody. In: Meslin JB, Kaplan MM, Koprowski H. Laboratory techniques in Rabies. World Health Organization. Geneva, 1996. p.476.

59. Souza Junior MF, Lobato ZIP, Lobato FCF, Moreira EC, Oliveira RR, Leite GG, Freitas TD, Assis RA. Presença de anticorpos da classe IgM de Leptospira interrogans em animais silvestres do Estado do Tocantins, 2002. Rev Soc Bras Med Trop 39: 292-294, 2006.

60. Sterner RT, Meltzer MI, Shwiff SA, Slate D. Tactics and economics of wildlife oral rabies vaccination, Canada and the United States. Emerg Infect Dis 15: 1176-1184, 2009.

61. Teixeira RHF, Ambrosio SR. Carnívora - Procyonidae (quati, mão-pelada, jupará). In: Cubas ZS, Silva JCR, Catão-Dias JL. Tratado de animais selvagens. Roca. São Paulo, 2007. p. 1376.

62. Thoisy B, Gardon J, Salas RA, Morvan J, Kazanii M. Mayaro virus in wild mammals, French Guiana. Emerg Infect Dis 9: 1326-1329, 2003.

63. Vieira AS. Levantamento de Leptospira spp em animais silvestres do pantanal sul-mato-grossense por meio de técnicas sorológicas e moleculares. Campo Grande [Dissertação de Mestrado em Ciência Animal - FMVZ/UFMS], 2009.

64. Voltarelli EM, Arraes SMAA, Perles TF, Lonardoni MVC, Teodoro U, Silveira TGV. Serological survey for Leishmania sp. infection in wild animals from the municipality of Maringá, Paraná state, Brazil. J Venom Anim Toxins incl Trop Dis 15: 732-744, 2009.

65. Wanke B, Londero AT. Epidemiology and paracoccidioidomycosis infection. In: Franco M, Lacaz CS, Restrepo A, Del Negro G. Paracoccidioidomycosis. CRS Press. Boca Raton, 1994. p.109-120.

66. Wilson DE, Reeder DAM. Mammal Species of the World. A Taxonomic and Geographic Reference. Johns Hopkins University Press. Baltimore, 2005. p.2142. 


\section{PRÓXIMOS EVENTOS NA ÁREA DE PATOLOGIA TROPICAL E SAÚDE PÚBLICA \\ MEETINGS TO BE HELD ON THE AREA OF TROPICAL PATHOLOGY AND PUBLIC HEALTH}

XVIII International Congress for Tropical Medicine and Malaria and XLVIII Congress of the Brazilian Society for Tropical Medicine, Rio de Janeiro, 23 to 28th September 2012. Informações: http://ictmm2012.ioc.fiocruz.br/index.html

XXVIII Reunião Anual da Sociedade Brasileira de Protozoologia e XXXIX Reunião Anual de Pesquisa Básica em Doença de Chagas, de 1 a 3 de outubro de 2012, Caxambu, MG. Informações: http://www.sbpz.org.br/

XXII Encontro Nacional de Virologia e VI Encontro de Virologia do MERCOSUL, de 23 a 26 de outubro de 2012, Atibaia-SP. Informações: http://sbv. dominiotemporario.com/web2/enc_nac_virologia2012/index.html

XXI Congresso Latino-Americano de Microbiologia - CLAM 2012, de 28 de outubro a 1 de novembro de 2012, Santos, SP. Informações: http://www. sbmicrobiologia.org.br/Latino/

X Congresso Brasileiro de Saúde Coletiva de 14 a 18 de novembro de 2012, Porto Alegre, RS. Informações: http://www.abrasco.org.br/noticias/noticia_int. php?id_noticia $=725$

II Simpósio Brasileiro de Toxoplasmose, São Paulo, Brasil, 30 de janeiro a 01 de fevereiro, 2013. Informações: http://www.toxobrasil.com.br/

V Word Congress on Leishmaniasis, Porto de Galinhas, Pernambuco, Brazil, 13 to 17 may 2013. Information: http://www.worldleish5.org/?page_id=2

$8^{\text {th }}$ European Congress on Tropical Medicine and International Health, Copenhagen, 10 to 13 September, 2013. Information: http://www.ectmih2013.dk/

XXI Congreso Latinoamericano de Parasitologia, FLAP, Guayaquil, Ecuador, 6 a 9 de Octubre, 2013. Informações: http://flap2013.com/

XXIII Congresso Brasileiro de Parasitologia, de 22 a 27 de outubro de 2013, Florianópolis, SC. Informações: www.parasitologia.org.br

XIII ICOPA, International Congress of Parasitology, Mexico City, Mexico, 10 to 15 august, 2014. Information: http://www.icopa2014.com/index.php?link=welcome 